\title{
POTENTIAL BENEFITS AND BUSINESS VALUE OF BIG DATA ANALYTICS
}

\author{
Dewi Sri Woelandari P.G \\ Ph.D Student of Economics and Business Universitas Diponegoro Semarang dan \\ Department of Management Universitas Bhayangkara Jaya \\ Email: wulanekodjoyo@gmail.com
}

\section{ARTICLE INFO}

Keywords:

Big Data Analytic, Business

Value,

Business Organization

\section{ABSTRACT}

Perkembangan teknologi informasi semakin memudahkan organisasi bisnis untuk dapat mengakses teknologi informasi secara cepat dan real time, sehingga organisasi bisnis dapat melakukan feedback atau respon yang lebih cepat mencari solusi terhadap keluhan pelanggan. Hal ini dapat dilakukan dengan menggunakan big data analytics (BDA). Big data merupakan sebuah kombinasi teknologi yang dapat mengelola data yang beragam dalam jumlah besar dengan kecepatan yang tepat dan pada saat yang tepat untuk keperluan analisis dan reaksi. Tujuan dari penelitian ini adalah menggali lebih jauh potensi manfaat dan nilai bisnis dari big data analytics (BDA) dalam organisasi bisnis dengan berbasis pada kajian literatur. Hasil kajian literatur dari studi ini merupakan kerangka konseptual (kontribusi teoritis) yang akan dikembangkan untuk penelitian lebih lanjut.

\section{INTRODUCTION}

Data memiliki peran penting dalam pengambilan keputusan strategi terutama ketika memasuki era ledakan data/data besar (big data), dimana perusahaan-perusahaan dalam berbagai sektor diharuskan menangani sejumlah data besar (big data), hal ini dikarenakan data yang besar (big data) dapat menawarkan wawasan yang sangat berharga selain itu juga menawarkan keunggulan kompetitif jika sumber daya teknologi dan organisasi mendukung mereka (Morabito, 2015). Oleh karena itu pihak-pihak yang mampu mengolah dan memanfaatkan data-data yang tersedia dalam volume besar, cepat berubah, keragaman variatif, dan komplekstas yang tinggi serta kecepatan penambahan data yang tinggi dapat mengambil keuntungan yang besar dengan mengacu pada manfaat besar yang ditawarkan oleh teknologi big data. Namun sayangnya penerapan big data analytics masih belum begitu populer di Indonesia.

Big data adalah data yang melebihi proses kapasitas dari sistem database yang ada. Data terlalu besar dan terlalu cepat atau tidak sesuai dengan struktur arsitektur database yang ada, sehingga untuk mendapatkan nilai dari data, maka harus memilih jalan alternatif untuk memprosesnya. 
Melalui teknologi informasi, triliunan byte data diciptakan setiap hari dari berbagai sumber, seperti dari media sosial, video surveillance, dan smart grids. Lautan data ini mengarah pada satu terminologi yaitu big data. Sejauh ini hanya ada tiga bidang usaha yang merupakan pengguna utama big data di Indonesia yaitu perusahaan telekomunikasi, perbankan, dan produsen barang-barang konsumsi ringan dan murah, seperti minuman dan makanan kemasan (consumer goods)

Para praktisi yang melakukan studi tentang big data analytics menekankan perlunya memahami bagaimana, mengapa dan kapan aplikasi big data analytics (BDA) dapat menjadi sumber yang sangat berharga bagi perusahaan untuk mendapatkan keunggulan kompetitif (Abbasi, Sarker, \& Chiang, 2016; Agarwal \& Dhar, 2014; dan Corte Real, Oliveira \& Ruivo, 2014).

Meskipun teknologi big data analytics telah diakui sebagai hal besar setelah inovasi (yaitu merupakan sumber potensial nilai bisnis dan keunggulan kompetitif), namun rantai nilai big data analytics relatif belum terjamah dan perlu diselidiki lebih lanjut. Menurut Abbasi et al (2016), masih belum ada penelitian empiris yang menilai bagaimana big data analytics dapat membawa nilai bisnis (business value) bagi perusahaan. Selain itu menurut Corte Real et al (2014), belum ditemukan penelitian tentang bagaimana big data analytics dapat membangun hubungan antara aset pengetahuan, kelincahan organisasi dan kinerja (tingkat proses dan keunggulan kompetitif).

Meskipun literature potensi bisnis big data analytics berkembang pesat, namun dalam studi empiris teori big data terbatas hanya digunakan dalam domain nilai bisis IT (Gupta \& George, 2016). Menurut Constantiou \& Kallinikos (2015), untuk memperoleh implikasi teoritis dan praktek serta untuk memahami area penelitian dimasa depan, kiranya penting untuk menempatkan studi saat ini dalam kerangka kerja penelitian dan memahami bagaimana artefak inti dibentuk serta bagaimana mengarahkanhya ke business value.

Teknologi big data tidak hanya dapat dimanfaatkan oleh perusahaan-perusahaan besar, namun juga oleh usaha-usaha kecil dan menengah (UMKM) maupun organisasi publik. Meskipun teknologi big data terbilang rumit dan mahan, namun perusahaan kecil dapat juga memanfaatkan big data asalkan tahu persis apa tujuan bisnisnya, sehingga memudahkan proses identifikasi data yang dibutuhkan serta mendapatkan manfaat yang lebih besar dari investasi yang dikeluarkan.

Chrisvania (2017), menyatakan bahwa big data yang diimplementasikan oleh perusahaan besar umumnya digunakan secara multi fungsi, dengan implementasi ini analisa baru digunakan untuk suatu kepentingan tanpa mengubah infrastruktur yang sudah mereka bentuk secara signifikan. Namun bagi perusahaan menengah atau SME (small medium entreprise) mereka mengimplementasi big data untuk menganalisis suatu keperluan tertentu secara spesifik atau terperinci.

Tulisan ini mencoba untuk menawarkan solusi pemanfaatan big data analytics yang dapat digunakan untuk membawa nilai bisnis bagi usaha-usaha kecil menengah di Indonesia, sehingga kinerja bisnis UMKM semakin meningkat. 


\section{LITERATUR REVIEW}

Diskusi tentang big data telah menjadi isu yang menrik dalam beberapa tahun terakhir. Masalah ini menjadi sorotan karena munculnya perdebatan diantara para ahli. Sampai saat ini, banyak yang berspekulasi kalau Big Data ini bukan hanya sebuah trend sesaat melainkan akan terus hits atau update dalam kurun waktu yang cenderung lama sama halnya dengan teknologi mobile (Chrisvania, 2017).

Big data diperkenalkan pertama kali oleh O'Reilly Media pada tahun 2015. Sebagian besar definisi big data fokus pada ukuran data dalam penyimpanan. Atribut penting dari big data selain ukuran adalah sebagai berikut:

1. Volume data

2. Variasi data

3. Kecepatan

3V big data merupakan definisi yang komprehensif dan mereka menggagalkan mitos bahwa data besar hanya tentang volume data, selain itu masing-masing dari 3V memiliki konsekuensi tersendiri untuk analitik (Russom, 2011).

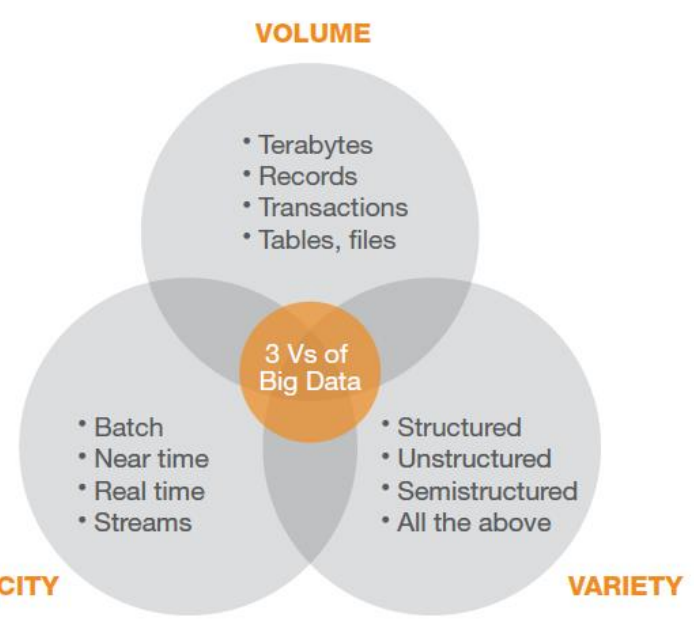

Big data adalah data berukuran besar yang volumenya akan terus bertambah dan terdiri dari berbagai jenis atau varietas data, terbentuk secara terus menerus dengan kecepatan tertentu dan harus diproses dengan kecepatan tertentu pula. Big data dapat juga didefinisikan sebagai data yang sangat sulit untuk dikoleksi, disimpan dan dikelola maupun dianalisa dengan menggunakan system database yang biasa karena volumenya akan terus berlipat. Dari segi teknologi, akan bermunculan pentingnya kemampuan untuk memproses big data.

Sedangkan menurut data Chandarana, Parth, \& Vijayakakshmi (2014), big mengacu pada 3V yaitu volume, variety, velocity dan ada yang menambahkan unsur $\mathrm{V}$ lainnya seperti veracity dan value. Volume (kapasitas data) berkaitan dengan ukuran media penyimpanan data yang sangat besar atau mungkin tidak terbatas hingga satuan petabytes atau zettabytes. Variety (keragaman data) terkait tipe atau jenis data yang 
dapat dioleh mulai dari data terstruktur hingga data tidak terstruktur, sedangkan velocity (kecepatan) terkait dengan kecepatan memproses data yang dihasilkan dari berbagai sumber, mulai dari data batch hingga real time, sementara itu karakteristik veracity (kebenaran)

Dalam mengimplementasikan teknologi Big Data di suatu organisasi, ada 4 elemen penting yang menjadi tantangan, yaitu data, teknologi, proses, dan SDM (Aryasa, 2015).

1. Data

Deskripsi dasar dari data menunjuk pada benda, event, aktivitas, dan transaksi yang terdokumentasi, terklasifikasi, dan tersimpan tetapi tidak terorganisasi untuk dapat memberikan suatu arti yang spesifik. Data yang telah terorganisir sehingga dapat memberikan arti dan nilai kepada penerima, disebut informasi. (Rainer, Kelly, \& Cegielski., 2009). Ketersediaan data menjadi kunci awal bagi teknologi Big Data. Ada beberapa organisasi yang memiliki banyak data dari proses bisnisnya yang dilakukan, baik data terstruktur maupun tidak terstruktur, seperti industri telekomunikasi maupun perbankan. Namun, ada pula organisasi yang perlu membeli atau bekerjasama dengan pihak lain untuk mendapatkan data.

2. Teknologi

Terkait degan infrastruktur dan tools dalam pengoperasian big data, biasanya organisasi atau perusahaan tidak akan mengalami kendala yang berarti dalam hal teknologi karena teknologi bisa didapatkan dengan membeli dan bekerja sama dengan pihak ketiga

3. Proses

Dalam proses mengadopsi teknologi big data dibutuhkan budaya organisasi. Misal: sebelum adanya big data, seorang pemimpin dalam menjalankan organisasi melakukan pengambilan keputusan hanya berdasarkan intuisi, nilai, keyakinan atau asumsi namun setelah adanya teknologi big data pemimpin mampu mengambil keputusan berdasarkan data yang akurat dan informasi yang relevan. Big Data dapat membantu melakukan analisis dan prediksi terhadap pelanggan yang akan menghentikan layanannya sehingga dapat ditindaklanjuti dengan mendengarkan kebutuhan pelanggan serta melakukan pencegahan di awal.

4. SDM

Dalam mengaplikasikan teknologi Big Data dibutuhkan SDM dengan keahlian analitik dan kreativitas yaitu kemampuan/keterampilan untuk menentukan metode baru yang dapat dilakukan untuk mengumpulkan, menginterpretasi dan menganalisis data, keahlian pemrograman komputer, dan ketrampilan bisnis yaitu pemahaman tentang tujuan bisnis. 


\section{BIG DATA ANALYTICS}

\subsection{Big Data Analytics: Past and Present}

Chen, Chiang, \& Storey (2012) menciptakan istilah Big Data Analytics (BDA), yaitu terkait bisnis \& analitik (BI \& A), dimana sebagian besar teknologinya menyangkut data mining dan analisis statistik. Literatur terbaru menunjukkan bahwa ada banyak ruang untuk penelitian BDA lebih lanjut (Abbasi et al., 2016; Agarwal \& Dhar, 2014; Erevelles, Fukawa, \& Swayne, 2016).

Lebih jauh Abbasi et al., 2016; Agarwal \& Dhar, 2014; Erevelles, Fukuwa, \& Swayne (2016) mengindikasikan bahwa masih banyak celah untuk penelitian-penelitian big data analytics lebih lanjut. Terkait nilai (value) sebagian besar studi akademis big data analytics fokus pada analisis nilai bisnis dari perspektif data atau sistem (LaValle et al., 2011; Kwon et al., 2014)

Istilah "big data" digunakan untuk pertama kalinya pada tahun 1997 oleh Michael Cox dan David Ellsworth dalam makalah yang dipresentasikan pada konferensi IEEE yaitu memaparkan tentang visualisasi data dan tantangan yang diajukan untuk sistem komputer.

Pada akhir 1990-an, inovasi teknologi informasi dan teknologi yang cepat memungkinkan pembangkitan data dalam jumlah besar tetapi sedikit informasi yang dapat digunakan untuk perbandingan. Periode 2001 hingga 2008 merupakan tahap evolusi untuk pengembangan data besar. Data besar pertama kali didefinisikan dalam hal volume, kecepatan, dan variasi (3V), setelah itu mulai dikembangkan perangkat lunak yang lebih canggih untuk memenuhi kebutuhan penanganan ledakan informasi.

Pada awal tahun 2009, big data analytics memasuki tahap revolusioner (Bryant et al., 2008). Big data tidak hanya menjadi terobosan inovasi komputasi, tetapi peneliti juga dapat memprediksi manajemen data terstruktur menjadi data tidak terstruktur dari lingkungan terminal statis beralih ke lingkungan berbasis cloud Tidak hanya memiliki komputasi data besar menjadi terobosan inovasi untuk intelijen bisnis, tetapi juga peneliti memprediksi bahwa manajemen data dan tekniknya adalah tentang untuk beralih dari data terstruktur menjadi data tidak terstruktur, dan dari lingkungan terminal statis ke lingkungan berbasis cloud di manamana.

Mengacu pada Gartner's (2013), trend IT solution di tahun 2016 memanfaatkan layanan komputasi dengan menggunakan big data analytics yang mendukung kemampuan analitic real time dan penyimpanan yang hemat biaya

\subsection{Tools of Big Data}

Menurut Alamsyah (2015), tools yang tersedia untuk penerapan big data dapat dikategorikan menjadi 2 yaitu: berbayar (personalized software) dan tidak berbayar (berbasis open source software). Tools tersebut berkaitan dengan 4 (empat) tahapan aktivitas dan dukungan teknologi pada Big Data yang mencakup (Alamsyah, 2015):

1. Acquired, berhubungan dengan sumber dan cara mendapatkan data. 
2. Accessed, berhubungan dengan daya akses data. Data yang sudah dikumpulkan memerlukan tata kelola, integrasi, storage dan computing agar dapat dikelola.

3. Analytic, berhubungan dengan informasi yang akan didapatkan, atau hasil pengelolaan data yang telah diproses. Analitik yang dilakukan dapat berupa descriptive (penggambaran data), diagnostic (mencari sebab akibat berdasar data), predictive (memprediksi kejadian dimasa depan) maupun prescriptive analytics (merekomendasikan pilihan dan implikasi dari setiap opsi).

4. Application terkait visualisasi dan reporting hasil dari analitik. Contoh application tool yang digunakan pada tahap ini yaitu R.Studio

Untuk perangkat lunak berbayar (proprietary software) yang mendukung big data analytics, hal ini menjadi model bisnis baru bagi beberapa vendor/perusahaan dengan menawarkan Big Data untuk menunjang pertumbuhan di industri lain. Seperti pada sebuah perusahaan telekomunikasi, yang menjadi penyedia jasa data analitik bagi beberapa instansi/lembaga pemerintah pusat dan daerah, industri penerbangan, dan kesehatan.

Penelitian ini memperluas penelitian nilai bisnis dari perspektif strategi manajemen.melalui penelitian empiris dengan menilai big data analytics.

\subsection{Big Data Analytics and Business Value}

Menurut Davenport (2006), dalam konteks big data, sangatlah penting untuk mengidentifikasi berbagai jenis sumber daya, karena keberagaman bisnis dapat menjadi sumber diferensiasi kompetitif (source of competitive differentiation). Beberapa penelitian mendefinisikan building blocks perusahaan terkait big data analytics capability adalah membangun sumber daya yang diperlukan ((McAfee et al., 2012; Kamioka \& Tapanainen, 2014; Gupta \& George, 2016; Wamba et el., 2017), namun demikian mayorita studi masih mengadopsi konsep dari literatur IT dan masih sedikit studi yang mengkhususkan pada konteks big data.

Sebagian besar penelitian saat ini masih terfragmentasi, sehingga sulit mengevaluasi nilai bisnis (business value), misal Kaisler et al (2013) melakukan identifikasi penyimpangan data dan transportasi data sebagai aspek penting berkaitan dengan nilai big data. Dalam penelitian ini peneliti berusaha untuk mengintegrasikan dari perspektif teoritis dan dikombinasikan dengan literature yang ada terkait big data analytics dan mengkaji lebih dalam pentingnya perusahaan mendorong kapabilitas organisasi.

\subsection{Potential Benefits of Big Data Analytics}

Saat ini organisasi yang mengadopsi big data analytics sudah dalam jumlah yang besar. Faktor penentu dari manfaat-manfaat potensial dari big data analytics adalah mendorong organisasi atau perusahaan mengadopsi big data analytics. Russom (2011) menyatakan bahwa segala bentuk keterlibatan dengan konsumen big data analytics dapat memberikan manfaat. Bisnis intelegen secara umum dapat memberi manfaat dengan menggunakan big data analytics. 
Tiga alasan Shang and Seddon (2002) mengklasifikasikan potensi manfaat dari big data analytics, antara lain adalah sebagai berikut: (1) memberikan seperangkat manfaat spesifik dari sub dimensi big data analytics, yang dapat membantu mengidentifikasi manfaat perkategori, (2) kerangka kerja didesain untuk para manajer dalam menilai manfaat dari sistem enterprise perusahaan, (3) memberikan klasifikasi dan panduan yang jelas manfaat-manfaat dari sistem enterprise perusahaan.

Menurut Chrisvania (2017), manfaat-manfaat yang bisa digunakan oleh perusahaan dengan mengimplementasikan big data adalah sebagai berikut, (1) analisis data sosial (social data analysis), (2) Analisis data riwayat (historical data analysis), dan (3) analisis prediksi (predictive analysis).

Beberapa manfaat big data yang sudah dirasakan khususnya bagi dunia usaha diantaranya untuk mengetahui respons masyarakat terhadap produk-produk yang dikeluarkan melalui analisis sentimen di media sosial; membantu perusahaan mengambil keputusan secara lebih tepat dan akurat berdasarkan data; membantu meningkatkan citra perusahaan di mata pelanggan; untuk perencanaan usaha dengan mengetahui perilaku pelanggan, seperti pada perusahaan telekomunikasi dan perbankan; serta mengetahui tren pasar dan keinginan konsumen.

Selain bermanfat untuk analisis bisnis, teknologi Big Data juga dapat dimanfaatkan secara luas di pemerintahan. Beberapa peluang pemanfaatan Big Data di sektor publik antara lain untuk mendapatkan feedback dan respon masyarakat dari sistem informasi layanan pemerintah maupun dari media sosial, sebagai dasar penyusunan kebijakan dan perbaikan pelayanan publik; menemukan solusi atas permasalahan yang ada berdasarkan data, contohnya dengan menganalisa informasi cuaca dan tingkat kesuburan tanah, pemerintah dapat menetapkan atau menghimbau jenis varietas tanaman yang ditanam oleh petani pada daerah dan waktu tertentu; serta membantu dalam manajemen dan pengawasan keuangan negara.

Mengacu pada besarnya manfaat yang dapat ditawarkan oleh tren teknologi big data, dan tantangan apa saja yang muncul dalam penerapannya. Penerapan teknologi big data pada suatu organisasi atau perusahaan dapat dilihat dari fungsi-fungsi yang sudah tersedia pada IT infrastrukturnya, sehingga dapat menjalankan kerja yang berhubungan dengan aplikasi mobile, social, dan big data analytics. Diharapkan hasil kajian dapat memberikan informasi dan inspirasi sehingga implementasi teknologi big data di Indonesia dapat semakin luas.

\section{CONCLUSIONS}

Big data analytica (BDA) memberikan nilai bisnis pada perusahaan dalam berbagai cara dan banyak ahli mulai menyoroti perlunya memahami keunggulan kompetitif, dalam hal ini berkaitan dengan bagaimana memahami rantai nilai dari big data analytics.

Ketersediaan data skala besar dan murah dewasa ini mendorong berbagai pihak untuk memanfaatkannnya melalui implementasi big data analytics. Peluang dan manfaat penerapan big data sangat potensial baik di organisasi bisnis maupun organisasi publik. Dengan menggunakan data, strategi bisnis maupun kebijakan publik bisa didesain dan diimplentasikan lebih efektif dan tepat untuk mencapai sasaran.

Dewi Sri Woelandari P.G (Potential Benefits And Business Value Of Big Data Analytics...) 


\section{REFERENCES}

Abbasi, A., Sarker, S., Chiang, R.H.L., 2016. Big data research in information systems: toward an inclusive research agenda. J. Assoc. Inf. Syst. 17, 1-32.

Agarwal, R., Dhar, V., 2014. Editorial—big data, data science, and analytics: the opportunity and challenge for IS research. Inf. Syst. Res. 25, 443-448.

Alamsyah, A. (2015). (Big) Data Analytics for Economics, Business and Management: A Social Network Approach. In Workshop Big Data Puslitbang Aptika dan IKP,tanggal 19 Mei 2015. Puslitbang Aptika dan IKP.

Aryasa, K. (2015). Big Data: Challenges and Opportunities. In Workshop Big Data Puslitbang Aptika dan IKP, tanggal 19 Mei 2015. Puslitbang Aptika dan IKP.

Bryant, R.E., Katz, R.H., Lazowska, E.D., 2008. Big-data computing: creating revolutionary breakthroughs in commerce, science, and society computing. Computing Research Initiatives for the 21st Century. Computing Research Association (Available at http://www.cra.org/ccc/files/docs/init/Big_Data.pdf).

Chandarana, Parth, \& Vijayalakshmi, M. (2014). Big Data analytics frameworks: Circuits, Systems, Communication and Information Technology Applications (CSCITA). In International Conference on IEEE 2014. IEEE.

Chen, H., Chiang, R., \& Storey, V. (2012). Business intelligence and analytics: From Big Data to big impact. MIS Quarterly, 36(4), 1165-1188.

Chrisvania, N. (2017). Social media and technology's impact on business, society, and culture. https://socialmediaweek.org/jakarta/2017/01/06/strategi-dalam-implementasi-big-data/.

Constantiou, I.D. and Kallinikos, J., 2015. "New games, new rules: big data and the changing context of strategy", Journal of Information Technology (30:1), pp.44-57.

Corte Real,N., Oliveira, T., \& Ruivo, P. (2014). Understanding the hidden value of business intelligence and analytics (BI\&A). Twentieth American Conference of Information Systems. Savannah, Georgia: Association of Information Systems.

Davenport, T.H., 2006. “Competing on analytics”, Harvard Business Review (84:1), p.98.

Erevelles, S., Fukawa, N., \& Swayne, L. (2016). Big Data consumer analytics and the transformation of marketing. Journal of Business Research, 69(2), 897-904.

Gartner, 2014. Gartner SaysWorldwide IT Spending on Pace to Grow 3.2 Percent in 2014.

Gupta, M. and George, J.F., 2016. "Toward the development of a big data analytics capability", Information \& Management (53:8), pp.1049-1064. Janssen 
Kaisler, S., Armour, F., Espinosa, J.A. and Money, W., 2013. "Big data: Issues and challenges moving forward”, in System sciences (HICSS), 2013 46th Hawaii international conference on (pp. 9951004). IEEE

Kamioka, T. and Tapanainen, T., 2014. "Organizational Use of Big Data and Competitive AdvantageExploration of Antecedents", in PACIS 2014: 18th Pacific Asia Conference on Information Systems. Association for Information Systems. AIS Electronic Library (AISeL) (p. 372).

Kwon, O., Lee, N., \& Shin, B. (2014). Data qualitymanagement, data usage experience and acquisition intention of Big Data analytics. International Journal of Information Management, 34(3), 387-394.

Lavalle, S., Lesser, E., Shockley, R., Hopkins, M.S., Kruschwitz, N., 2011. Big data,analytics and the path from insights to value. Mit. Sloan Manag. Rev. 52, 21-32.

McAfee, A., Brynjolfsson, E., Davenport, T.H., Patil, D.J. and Barton, D., 2012. "Big data. The management revolution", Harvard Business Review (90:10), pp.61-67.

Morabito, V. (2015). Big Data and analytics: Strategic and organizational impacts. Springer.

Rainer, Kelly, R., \& Cegielski., C. G. (2009). Introduction to Information Systems. John Wiley \& Sons (Asia) Pte Ltd.

Russom, P. (2011). The Three Vs of Big Data Analytics. TDWI

Shang, S., Seddon, P.B., 2002. Assessing and managing the benefits of enterprise system: The business manager perspective. Inf. Syst., J. 12 (4), 271-299.

Wamba, S.F., Gunasekaran, A., Akter, S., Ren, S.J.F., Dubey, R. and Childe, S.J., 2017. "Big data analytics and firm performance: Effects of dynamic capabilities", Journal of Business Research (70), pp.356-365. 